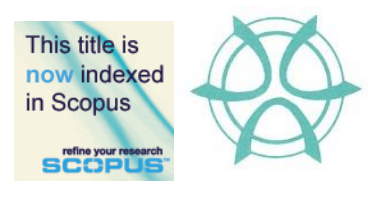

\title{
THE IMPACT OF GENTRIFICATION ON LOCAL URBAN HERITAGE IDENTITY IN OLD QUARTER, MELAKA HERITAGE CITY
}

\author{
Raja Norashekin Raja Othman ${ }^{1}$ \\ ${ }^{1}$ Faculty of Architecture, Planning and Surveying \\ UNIVERSITI TEKNOLOGI MARA (UiTM)
}

\begin{abstract}
Gentrification represents a new trend of development towards the new forms of socio-spatial divisions of the city centre. It also restores the quality of urban development and life of the local community. However, there are various issues arising from this developmental process. These issues have been identified as the demand for physical development, economic worth and sociological evaluation of the community, which have an effect on the local identity of the study area. Therefore, the aim of this paper is to identify the impact of gentrification on the local urban heritage identity in the heritage city of Melaka. The study takes a quantitative research approach. This study also shows the positive and negative impacts to the local communities, and these effects may differ with other cities. The study evaluates the impact on the socio-culture and spatial structure in this area. Hence, recommendations of this paper place emphasis on the involvement of the local community in determining the direction of development. Apart from that, safeguarding the local intangible cultural heritage value in the urban development process should also be emphasised as it is intended to respect and protect the rights of the local community while creating a balanced development without compromising quality of cultural heritage assets of the historic city.
\end{abstract}

Keywords: cultural heritage, gentrification, heritage city, local community, urban identity

Date Received: $26^{\text {th }}$ July 2016

Date of Acceptance: $6^{\text {th }}$ July 2017 
Raja Norashekin Raja Othman

The Impact of Gentrification on Local Urban Heritage Identity in Old Quarter, Melaka Heritage City

\section{INTRODUCTION}

Gentrification is defined as an upgrading of the geographical area and the manifestation of middle-class values. It plays a significant role in the urban redevelopment sector (Bounds \& Morris, 2006; Butler, 2007; Danyluk \& Ley, 2007). Gentrification is a slow process and takes many years or in some cases, a decade for completion. It involves middle-class families shifting to economically deprived areas, where they purchase and restore the houses to raise property values. These new property values lead to higher rental rates and property taxes, and cause the displacement of the lower class families (Atkinson, 2000; Davidson $\&$ Lees, 2005). These issues are common in the urban redevelopment process in many developing countries and has sparked a universal debate on the reasons and impact of gentrification.

Like most cities, heritage cities are also affected by these processes. Heritage cities are usually linked with heritage preservation and is a significant part of the development process. Heritage preservation has customarily been viewed as the conservation, upkeep, renovation and refurbishment of buildings of a specific age (normally more than half a century), which are highly valued for their architectural charm or because of the people who were involved in the construction, design or related with different occupations of those buildings (Strange, 1999). However, heritage preservation involves much more than this. While the conventional perception of heritage preservation revolves not only around the building and its materials, it should also be extended to include the people, communities, stories, and the more detailed elements of the historical makeup for its reliability and validity (Hamnett, 2003; Lees, 1994)

Once a locality begins to degenerate, the historical buildings are usually vacated or simply left to crumble. But when gentrification occurs, the historical and domestic or common architecture of the buildings (particularly the houses) in a certain region or locality are preserved. This shows that the heritage preservation benefited in the process of gentrification. Gentrification restores the neighbourhood by repairing these historical buildings (Frank, 2005). This will drive up the resale value of the buildings, thus transforming the area and raising it to the level of the middle class, who are subsequently drawn to the area instead of avoiding them like in the past. Historical districts within cities are usually located in places where the urban housing values are cheap and populated with racial and ethnic minorities (Frank, 2005, Herman, 2009, Hamnett, 2003). Gentrification has a tendency to alter both of these features.

An uneasy relationship exists between gentrification and historic preservation, whereby the objective is usually to maintain the physical and social features of the area. Although gentrification may preserve the historical framework of a locality, it usually forces out the long-time residents, who cannot afford the higher rents, property taxes or upkeep of their buildings, and may avail the benefit of new facilities that come with the "upgraded" locality (Herman, 
PLANNING MALAYSIA:

Journal of the Malaysia Institute of Planners (2017)

2009, Herman, 2009, Hamnett, 2003) . Langegger (2016) has examined the gentrification need to link the social production of public space with the municipal regulation of public space.

This paper illustrates the effects of gentrification on the local urban identity of Melaka as a heritage city. The clash between gentrification and the local urban identity of a heritage city has become a major problem that needs to be tackled. It also gives a review on the historic cultural assets, which comprise tangible heritage and intangible cultural elements, factors that define the local identity of the area. The development trends in Melaka were examined in order to ascertain the requirements of urban development and tourism. The quality of the existing cultural buildings was also assessed to determine the value of the local identity.

\section{RESEARCH METHODOLOGY}

This study was conducted in the Old Quarter of the heritage city in Melaka. Melaka city was selected because it represents a different method of gentrification in a heritage area. The need for a study such as this arose out of the work to bring about social change, which has had an effect on the quality of the local identity.

This study adopted a quantitative research approach. Data was gathered from 148 respondents via face-to-face questionnaire survey. The respondents were those living and working in this area, where most of them are from similar backgrounds and have formed their own ideas about the community. The majority of the people in the area are Chinese because in the past this area functioned as a residential and business centre for traders. The Malays and Indians are the minority groups. Besides the questionnaire survey, the community leaders were interviewed to gather secondary data in order to further enhance the study.

Descriptive and inferential statistics tools in the Statistical Package of the Social Science (SPSS) software were used to analyse the data. The data was analysed within the context of the research objectives, which aims to critically assess the effect of gentrification on the local urban identity in the Old Quarter, Melaka.

The Old Quarter of Melaka city is a historic residential and commercial area in the World Heritage Site core zone. This area was developed more than 5 centuries ago and is an excellent example of a historic colonial town located along the Straits of Malacca. A series of physical and social advancements during the 1600 's to the 1800 's left behind historical vestiges such as memorials, historic passageways, heritage areas, buildings, and burial grounds. It also incidentally led to the creation of a distinctive mix-culture formed by interracial marriages and various religious observances with their way of life. Presently, this area has been identified as an attractive place for tourists and rapid development is taking place all around the area as urbanisation takes place. 
Raja Norashekin Raja Othman

The Impact of Gentrification on Local Urban Heritage Identity in Old Quarter, Melaka Heritage City

\section{FINDINGS AND DISCUSSION}

This section presents the analysis and findings of this study. This section also comprises a short discussion regarding the changes in the urban patterns and the challenges of gentrification in the study area based on the experience and views from the local community.

The study found that there were four main impacts of gentrification in the urban old quarter in Melaka city. These were identified through the views and opinions from the respondents. As shown in Table 1, gentrification in this area gives an impact towards changes of urban cultural heritage fabric (4.35), followed by the impact of decreasing the spirit of the place (4.27), Modification of social cultural value (3.85) and has created a Commodification of Cultural Heritage Value (3.71) in the study area.

Table 1 The Impact of Gentrification on Local Urban Heritage Identity

\begin{tabular}{lc}
\hline Impact & Means Value \\
\hline Changes of Urban Culture Heritage Fabric & 4.43 \\
Decreasing the spirit of the place - 'Genius Loci' & 4.27 \\
Modification of social Cultural Value & 3.85 \\
Commodification of Cultural Heritage Value & 3.71 \\
\hline
\end{tabular}

\section{Changes of Urban Culture Heritage Fabric}

Since its development began hundreds of years ago, the four unique races (Baba and Nyonya, Chitty, Malay and Portuguese) have been living peacefully together in one place, thus promoting prosperity, well-being and consumerism among them. Every space in this area has been created to bring the various communities together such as the shops, markets, streets or places of worship. The community utilises the location and space to varying degrees, creating an urban neighbourhood with a distinctive identity.

After Melaka city was recognised as a historical city and Melaka was placed on the list of World Heritage Sites, there was a strong support for the development of the area. The municipal council, together with the Melaka Heritage Trust and other NGOs, worked together to enhance these activities. These has resulted in high increase in revenues both from the development and also from the tourism industry.

The improved development over the past ten years has given rise to growing concerns with regards to the process of development and conservation. Variety of tourist attractions were developed in the area. At the same time, many traders or building owners were competing to develop their premises or properties for the purpose of tourism. This study found that $72 \%$ of the respondents have refurbished their building unit (Figure 1). Meanwhile, 28\% from the total respondents chose to preserve their building as it is. $17 \%$ of them are from the residential units. 
PLANNING MALAYSIA:

Journal of the Malaysia Institute of Planners (2017)

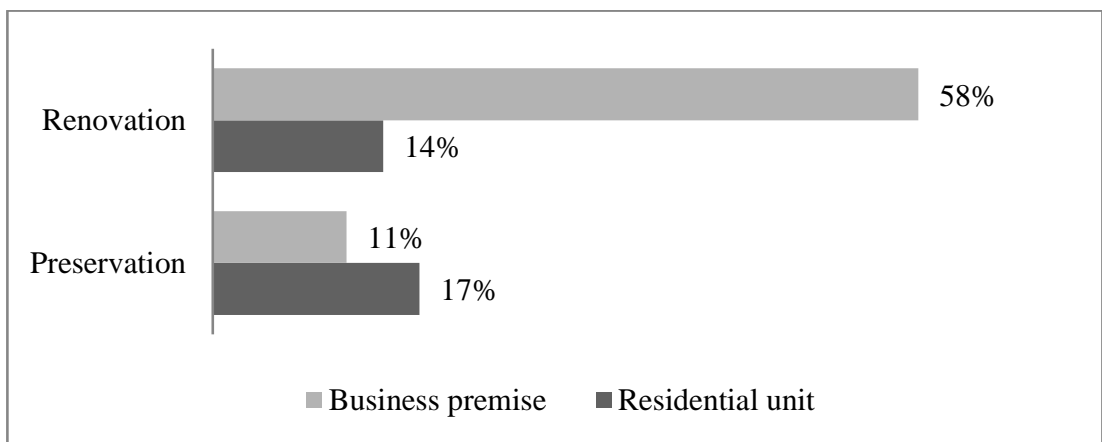

Figure 1 Building Refurbishment According to Building Use

Out of those respondents who have renovated their building unit, 35\% did it to enlarge the internal space, $27 \%$ to improve the comfort of the internal space, $23 \%$ because of building maintenance purposes and $15 \%$ for beautification of the interior and the exterior façade (Figure 2).

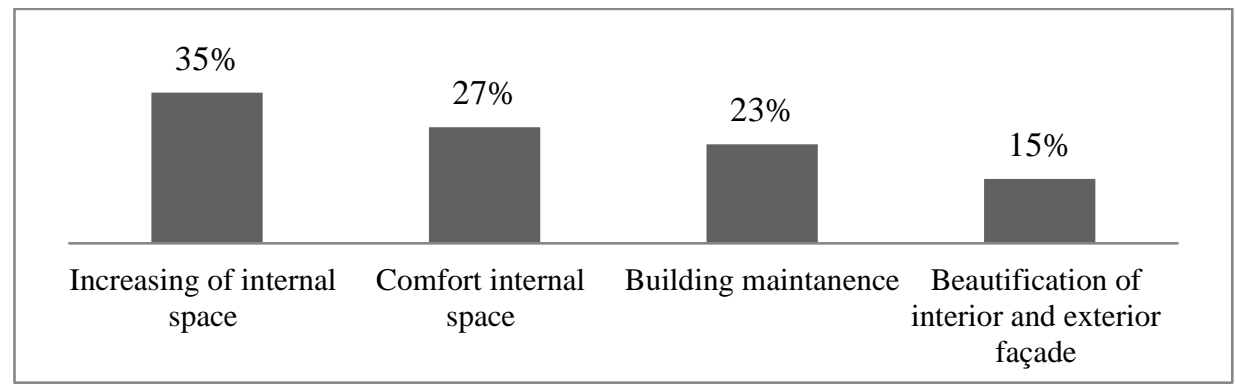

Figure 2 The Purpose of Building Renovation

In the study area, many ancient residential buildings have been refurbished into boutiques or budget hotels, and into cafés or restaurants, parallel with the current demand for tourism development. This, undoubtedly, has had positive and negative effect on the heritage quality of the built environment. Figure 3 shows that although almost half $(47 \%)$ of the respondents retain the existing building design during the renovation, $53 \%$ of the respondents who have renovated their building units have change the design of the building, either partially $(42 \%)$ or completely $(11 \%)$. Thus, although the distinctive old town image and identity of the study area have been mostly preserved, some building owners have failed to do the same to their building units. They merely maintained the front façade of the buildings in the original style, while the back of the buildings were not in accordance to the specifications laid out in the guidelines. Additionally, some of the public areas have now been designated as private areas. For example, some small streets or alleyways were closed for private purposes (building extension). This situation has led to a loss of publicly owned areas, thus 
Raja Norashekin Raja Othman

The Impact of Gentrification on Local Urban Heritage Identity in Old Quarter, Melaka Heritage City

limiting the social interactions/activities of the local community. These show that gentrification in this area has impacted the physical appearance of the historic centre and has played a role in changing the social fabric of the place.

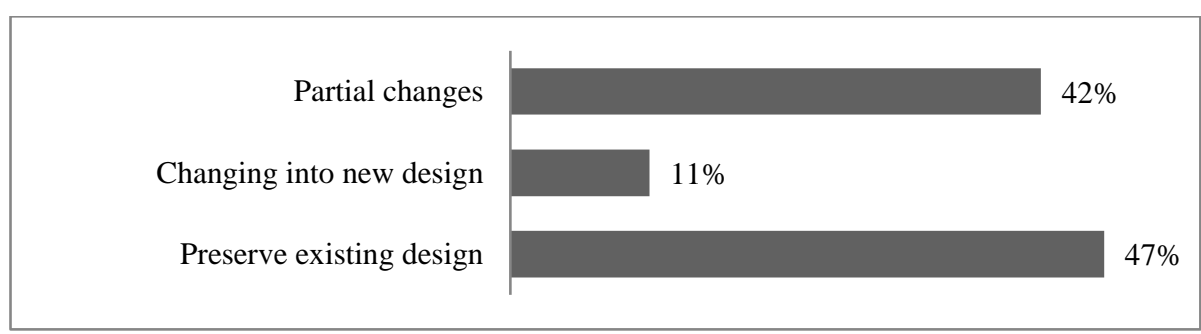

Figure 3 Building Renovation Pattern

\section{Decreasing 'The Spirit of the Place - Genius Loci'}

The Old Quarter has been a famous business district since the 1600's. It has become well-known among locals and tourists as a business district offering a range of daily essentials and services. For example, the wholesale and commercial centre of Melaka is located at Jalan Kampung Pantai, which claims to have the most number of retailers in town dealing with exclusive European and Chinese items. Here one can find traditional medicine halls, goldsmith shops, earthenware shops, wholesale liquor and tea companies, textile shops selling cheap Chinese materials, food stalls, milliners, shoemakers and pawnshops. The street is flourishing and business are brisk. The goods here are sold at much cheaper price than at other places due to the informal setting of the business premises. It is more interesting to shop in this district and shoppers/visitors can haggle over the price of the items they wish to purchase. This act of bargaining creates a special form of interaction between the shoppers and the traders, making this an attractive district for the local community and tourists alike.

The vibrancy of the district is heightened by the diversity of colours and sounds, and the flurry of activity among the hawkers and merchants, thus drawing crowds here, particularly during the festive seasons. In addition, as was stated earlier, every road or building section in the Old Quarter have their own character that is distinctive and exclusive to that area. This atmosphere is known as 'the spirit of the place' or 'genius loci'. It imbues the Old Quarter with a local urban identity of its own, which makes it a part of 'the outstanding universal value' of Melaka as a World Heritage Site.

However, the 'genius loci' of this district has been fading over the last five years. $81.8 \%$ of the respondents in this study concurred that this area has undergone a physical transformation that has affected the quality of the 'genius loci' and will have an impact on the local urban identity. Table 2 shows that most of the respondents agreed that the best place to meet is the coffee shop or 'kopitiam'. The oldest kopitiam in this district has been in existence since the 
1940s. In the kopitiams, local patrons can unwind and spend some time chitchatting, and playing mahjong or checkers while having some local traditional food. Most of these coffee shops are no longer there today. Some shut down after the owner passed away and no next-of-kin was willing to continue running the business. Some of the kopitiams have also been transformed into modern upscale outlet with the interiors have been refurbished accordingly. Most of the traders are more interested in fulfilling the demands of tourists rather than those of the locals. Currently, the local community is making less use of the kopitiams and thus, a part of the local urban identity is gradually vanishing.

Table 2 Proportion of Missing Elements and Their Relationship in Local Socio Community

\begin{tabular}{|c|c|c|c|c|c|c|c|c|c|}
\hline & Elements & 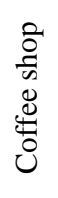 & $\bar{\Xi}$ & $\frac{\vec{d}}{\dot{\Xi}}$ & 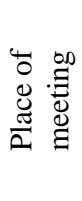 & 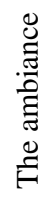 & 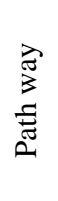 & 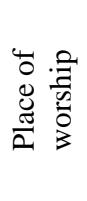 & 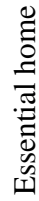 \\
\hline \multicolumn{2}{|c|}{ Missing Elements } & 24 & 16 & 10 & 18 & 21 & 5 & 4 & 1 \\
\hline \multicolumn{2}{|c|}{ Should Preserve } & 19 & 14 & 8 & 13 & 26 & 7 & 10 & 3 \\
\hline \multirow{4}{*}{ 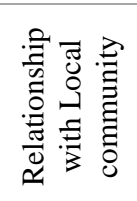 } & $\begin{array}{l}\text { Strong No } \\
\text { Relationship }\end{array}$ & 17 & 39 & 22 & 15 & 18 & 32 & 25 & 33 \\
\hline & No Relationship & 10 & 16 & 19 & 19 & 15 & 19 & 31 & 50 \\
\hline & Related & 51 & 34 & 41 & 31 & 44 & 43 & 19 & 17 \\
\hline & Strongly Related & 23 & 11 & 19 & 35 & 23 & 6 & 25 & 0 \\
\hline
\end{tabular}

Table 2 also shows that strong bond between the elements (coffee shops and the ambiance) and the social interaction among the local community. It has created a local urban identity and it is their hope that this element will be preserved to ensure that this identity will not be completely lost.

Local community also felt that urbanisation is one of the main causes for the fading genius loci. During interview, they revealed that modern businesses have indiscriminately defaced or removed buildings, revising the stories of the architecture, place, people and their lives. The departure of the local community leaves very little hope for its recovery. It is depressing for them to see their neighbourhood disappearing, with the people being forced to leave the place, where they were born and bred. There have been moments when they have felt uneasy in their own place because they feel 'unfamiliar' with the neighbourhood.

\section{Modification of Urban Socio-Culture}

Although the Old Quarter is located on prime land in the historic city of Melaka, property value was once considered low at between approximately RM700 (USD220) to RM1,250 (USD400) per square meter. However, since the repeal of 
Raja Norashekin Raja Othman

The Impact of Gentrification on Local Urban Heritage Identity in Old Quarter, Melaka Heritage City

the Rent Control Act 2000, the value went up to RM 5,000 (USD 1,600) and above per square meter (Jabatan Penilaian dan Perkhidmatan Harta, 2012). During interview, local community informed that some owners of business premises and residences located in this area are prepared to sell their property to either foreign or local investors in exchange for good profits. They are also prepared to move out from the area.

The increase in property value had also increased rent. As a result, some local tenants, who have been living here for the past 70 years, were recently forced to vacate their premises as they refused to pay the higher rental fees. Prior to this, they would often hold various cultural activities and celebrations of religious festivals here. They would feel happy if they could live among their people together, and they appreciated the culture and the history that they had inherited from their ancestors. They had created a life for themselves based on the expression of their local culture through their daily activities.

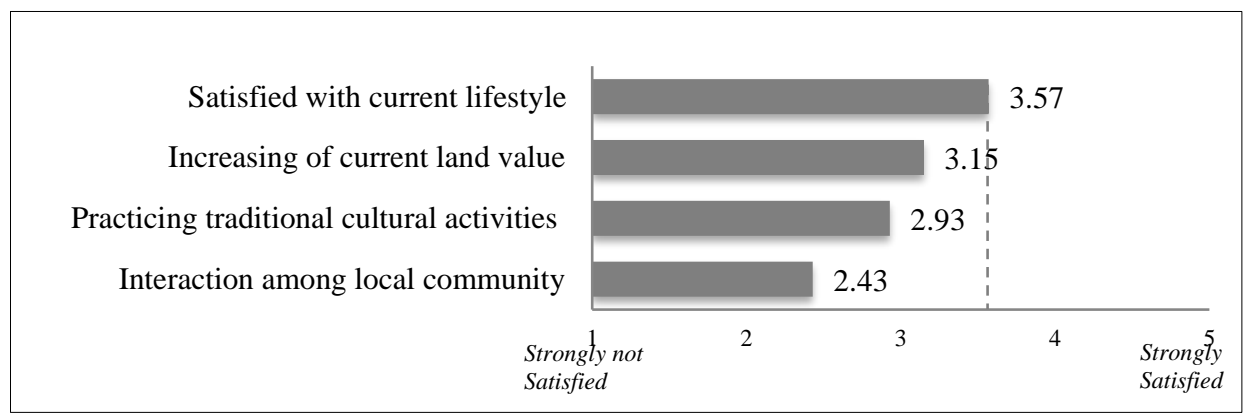

Figure 4 Urban Socio-Culture Life Satisfaction Level among Local Community in the Study Area

Figure 4 shows that majority of the respondents were satisfied with their current lifestyle (3.57 mean value), followed by satisfied with the increasing of current land value (3.15 mean value). However, respondents were not satisfied with the current practice of traditional values ( 2.93 mean value) and the level of interaction among local community (2.43 mean value). This indicates that gentrification has given both positive and negative impacts to the community socio-culture lifestyle. Many of the respondents were satisfied with their current lifestyle because they are earning monthly income through renting out their retail space. But many were not satisfied with the level of social interaction among the local community because most of the business operators are not locals who reside in the area. Instead, they just come to the area to operate their businesses during the day. During weekdays, when business is low, some areas are very quiet and create an uncomfortable feeling for some people. According to some respondents, this situation was less common in the last 20 years. Here it shows that a change in this area also affects the socio-culture of the local community. 


\section{Migration and Employment Opportunities}

The gentrification process has also encouraged the migration of outsiders into the area. Many foreign and local investors are interested in conducting their businesses here. The majority of them are running boutiques and budget hotels, cafes and restaurants, handicraft and souvenir shops, antique shops, art galleries and others. These are high-income generating businesses. This study has found that majority of the communities' traders $(60 \%)$ targeted their business to tourists, while only $40 \%$ aimed to serve both locals and tourists (Figure 5).

As they learn about the local culture, they also begin to appreciate and practice it in their daily lives. Surprisingly, more than half $(53 \%)$ of the respondents (traders) are selling local products. Some of the traders have been operating their family businesses here for more than sixty years. They have been involved in promoting products that reflect their tradition, culture and identity such as wooden clogs, 'baju kebaya', beaded shoes, wood carvings, batik paintings, and traditional toys and games. The modern craftsmen are also involved in this industry. In addition, cultural performances such as dances, traditional songs, theatre and martial arts, are often held in the area for tourists. The locals, belonging to various ethnic and age groups, participate in these performances. The NGOs are working together with the government to help in the promotion of these products and to make the facilities available to all.

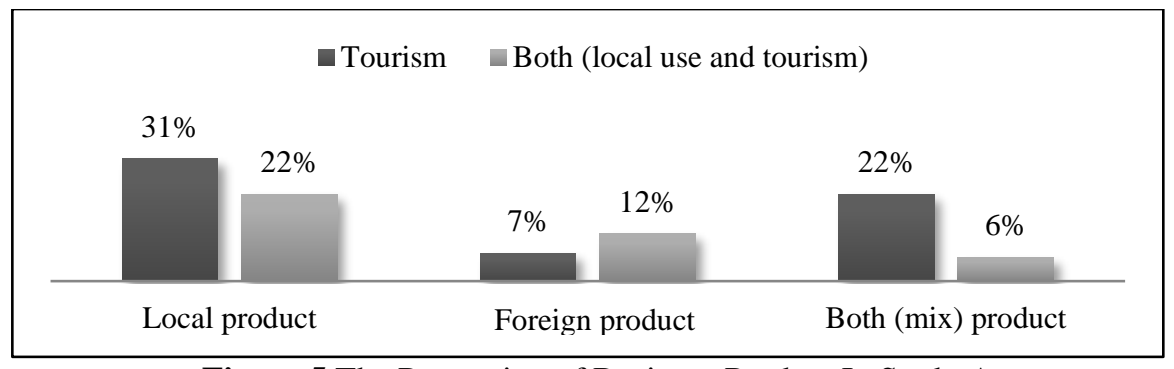

Figure 5 The Proportion of Business Product In Study Area

However, this study found that $19 \%$ of traders have been selling foreign product such as handicrafts and souvenirs from other countries, which do not reflect the local identity and image of the community. Here, it shows the process of gentrification formed on the commodification of local product and it is feared that this will affect the authenticity and image of traditional local products.

\section{RECOMMENDATION}

Based on the findings of this research, several recommendations are formulated. These recommendations may also be applicable to areas with similar characteristics and problems. 
Raja Norashekin Raja Othman

The Impact of Gentrification on Local Urban Heritage Identity in Old Quarter, Melaka Heritage City

\section{Local Community Participation}

Locals should be participating in the process of developing plans and policies for managing urban heritage. They are the experts of their own locality and have the right to be involved in the process. One of the suitable methods to use in developing urban heritage management policy is the Stakeholder Consultation Model, which is a community-based and holistic method. It focuses on the participation of the local community and organisations with regard the objectives of government policy because the locals are in agreement on the value of their cultural heritage.

\section{Building Ownership Control Policy}

The government needs to come up with a new policy to solve the problem of outside traders becoming owners of buildings in the area. The objective is to solve the marginalisation of minority groups (local community) and to protect the rights of the locals. In reaction to the gentrification process, the local government has to work with non-profit organisations and the private sector to provide assistance for long-time residents who want to continue living in their neighbourhoods.

\section{Consideration of Intangible Cultural Heritage Value in the Process of Urban Development}

The development process of heritage area must not only consider the tangible cultural heritage, but also the intangible ones. It is recommended that both types of heritage must be safeguarded so that balanced development can be achieved in the heritage area. In addition, preserving both tangible and intangible hertage assets can also help to retain the local population to stay in the area as well as to respect and protect the rights of the community. Indirectly, this will give a positive impact on the process of gentrification of the area.

\section{CONCLUSION}

Studies have shown that gentrification could be a recommended way of developing an urban heritage area. It benefits the area in several ways, especially in terms of heritage conservation and improved economic climate of the area. However, gentrification is not without its shortcomings. If uncontrolled, gentrification can dilute the image and identity of the area resulting in local community being marginalised and isolated in their own birth place. Gentrification has also been shown to replace locals with outsiders. In the case of Malacca, its 'living heritage' identity is the outstanding universal value for being listed as World Heritage Site. The local urban identity will be totally lost if the locals continue to move out from the area.

A sustainable urban heritage site is created when the 'spirit of the place' is maintained, the local urban identity is preserved and the rights of the community are protected. Urban planners and decision makers should not be guided merely 
PLANNING MALAYSIA

Journal of the Malaysia Institute of Planners (2017)

by the desire to earn high urban economic revenues, but they should work to preserve the Universal Outstanding Values of the heritage assets and protect the rights of the community. The key point here is, local community must be directly involved in determining the future direction of development in their urban heritage area.

Nevertheless, there are still some gaps to be filled in the future such as the lack of information and the limited sources of information. A higher level of research must be carried out quantitatively especially to identify the cause and effect, and the connection between the various cultural heritage elements and development pattern of the heritage area.

\section{ACKNOWLEDGEMENTS}

Special thanks to the Ministry of Higher Education for awarding the Fundamental Research Grant Scheme (FRGS -UiTM) and for providing their continuous support to this research endeavour. Deepest appreciation to all participants involved in the data collection process, from both the government agencies and the communities of Melaka Heritage City.

\section{REFERENCES}

Atkinson, R. (2000). Measuring gentrification and displacement in Greater London. Urban Studies, 37(1), 149-165.

Bounds, M., \& Morris, A. (2006). Second wave gentrification in inner-city Sydney. Cities, 23(2), 99-108.

Butler, T. (2007). For gentrification? Environment and Planning A, 39(1), 162181.

Danyluk, M., \& Ley, D. (2007). Modalities of the new middle class: ideology and behaviour in the journey to work from gentrified neighborhoods in Canada. Urban Studies, 44(11), 2195-2210.

Davidson, M., \& Lees, L. (2005). New-build 'gentrification' and London's riverside renaissance. Environment and Planning A, 37, 1165-1190.

Frank, S. B. (2005). If we own the story, we own the place: cultural heritage, historic preservation, and gentrification on U Street (Master's thesis). University of Maryland, College Park, USA.

Hammnett, C. (2003). Gentrification and the middle class remarking of Inner London, 1961-2001. Urban Studies, 40(12), 2401-2426.

Herman L. B (2009). Toward a theory of gentrification (Doctorate dissertation). Miami University, Ohio, USA.

Jabatan Penilaian dan Perkhidmatan Harta (2012). Property market report. Kuala Lumpur: JPPH.

Lees, L. (1994). Gentrification in London and New York: An Atlantic gap? Housing Studies, 9(2), 199-217. 
Raja Norashekin Raja Othman

The Impact of Gentrification on Local Urban Heritage Identity in Old Quarter, Melaka Heritage City

Strange, I. (1999). Urban sustainability, globalisation and the pursuit of the heritage aesthetic. Planning Practice and Research, 14(3), 301-11

Langegger, S. (2016). Right-of-way gentrification: conflict, commodification and cosmopolitanism. Urban Studies, 53(9), 1-19. 